\title{
Gestão de tecnologia em universidades: uma análise do patenteamento e dos fatores de dificuldade e de apoio à transferência de tecnologia no Estado de São Paulo
}



Leonardo Augusto Garnica

Ana Lúcia Vitale Torkomian

\section{Resumo}

A gestão da tecnologia nas universidades públicas brasileiras tem ganhado crescente importância para o sistema de inovação brasileiro. A Lei de Inovação de 2004 forneceu diretrizes legais específicas acerca da propriedade intelectual, cooperação técnica e transferência tecnológica favorecendo a intensificação desses processos. O objetivo deste trabalho foi apreender as políticas institucionais e os desafios para a transferência de tecnologia em universidades públicas do Estado de São Paulo, a saber: USP, Unesp, Unicamp, Unifesp e UFSCar, buscando identificar fatores de dificuldade e de apoio em processos de transferência de tecnologia observados pelos agentes das universidades e empresas parceiras. A pesquisa, de tipo qualitativa, utilizou-se da estratégia de estudo multicaso e por meio da realização de entrevistas a respeito de contratos de transferência de tecnologia foi realizada análise comparativa das universidades. Verificou-se um crescimento do patenteamento e da atividade de comercialização de tecnologia em todos os casos, porém ainda recentes.

Palavras-chave: Gestão de tecnologia. Universidades públicas. Propriedade intelectual.

\section{Introdução}

Tendo em vista o papel decisivo da inovação para o desenvolvimento tecnológico e econômico dos países, especialmente após a metade do século XX, o tema da gestão de tecnologia tem se mostrado de crescente importância. Diversas têm sido as perspectivas de análise dessa gestão que visa o melhor aproveitamento de novas tecnologias para as organizações desenvolvedoras e aplicadoras desses conhecimentos novos, sendo as duas principais: aquela que visa o desenvolvimento de novos produtos, mais relacionada ao contexto da firma, e aquela que se refere às tecnologias geradas em instituições que fazem $P \& D$, mas não implementam primordialmente novas tecnologias na forma de produtos, isto é, universidades e institutos de pesquisa.

No Brasil, de forma especial, os investimentos em P\&D como proporção do PIB tem crescido nos últimos anos, tendo sido de 1,3\% em 2000 e 1,41\% em 2007 (MCT, 2009), no entanto esse investimento ainda pode ser considerado baixo. Em valores absolutos no ano de 2008, o Brasil gastou US\$22,8 bilhões enquanto que, considerando dados de 2007, os Estados Unidos gastaram aproximadamente US\$ 368 bilhões, o Japão cerca de US\$ 147,8 bilhões e a
Coreia US\$ 41,7 bilhões (MCT, 2009). No caso brasileiro, a maior parte desse gasto é realizada pelo setor público, tendo correspondido no ano de 2007 a 53,93\%, enquanto que o setor empresarial, incluindo empresas públicas e demais instituições, 46,07\% (MCT, 2009). Como indicativo, deve-se ressaltar que aproximadamente $30 \%$ do total de gastos em P\&D são feitos em instituições do ensino superior, ou seja, universidades públicas, tendo por isso evidência a relevância dessas instituições para a busca de novas tecnologias no contexto brasileiro (MCT, 2002) bem como para a internalização de P\&D nas empresas a partir dessas instituições.

A utilização do conhecimento gerado nas universidades brasileiras representa rica fonte de informação e capacitação para o desenvolvimento de novas tecnologias, resultando no fato de que a transferência de tecnologia entre universidade e setor produtivo consiste em um caminho alternativo e complementar para o alcance de um patamar tecnológico superior das empresas brasileiras. Entre as diversas formas de transferência de tecnologias resultantes da pesquisa acadêmica, destacam-se o licenciamento de patentes e a criação de novas empresas - spin-offs, sendo que tais 
mecanismos formais de transferência de conhecimentos e transformação em bens disponíveis ao mercado têm sido considerados a mudança mais significativa nas relações universidade-empresa (U-E) nos últimos anos (GUSMÃO, 2002).

Esses mecanismos têm sido objeto de estudos em países desenvolvidos, tais como EUA e Inglaterra (FRIEDMAN; SILBERMAN, 2002; GRAFF; HEIMAN; ZILBERMAN, 2002; LOCKETT et al., 2005; MCADAM, 2004; MARKMAN et al., 2005; MOWERY et al., 2001).

No Brasil, entretanto, há um atraso de mais de duas décadas em relação a essas questões (STAL; FUJINO, 2002), de forma que o debate sobre esses mecanismos de transferência de tecnologia no âmbito organizacional e legal ainda precisa avançar.

A transferência de tecnologia tem recebido atenção especial após a Lei de Inovação Brasileira, Lei no 10.973 regulamentada em 2005, a qual dispõe, dentre outros temas, sobre o estímulo à inovação por meio da colaboração entre o sistema público de Ciência e Tecnologia e o setor empresarial. Sua importância pode ser vista também pelo fato de que a ausência de diretrizes legais específicas por parte do governo brasileiro quanto às parcerias universidade e indústria no período anterior resultaram em entraves para a transferência de tecnologia direta com foco no licenciamento de patentes, pois havia dúvidas de caráter jurídico quanto à aplicação da Lei de Propriedade Industrial (n ${ }^{\circ}$ 9279/96) no tocante à retenção pelas universidades dos direitos de patente e também quanto à legalidade de contratos com o setor empresarial para exploração das tecnologias desenvolvidas em universidades públicas (FUJINO; STAL, 2004).

Entretanto, neste novo contexto, o momento atual é de uma adequação das estruturas acadêmicas que visa ao aperfeiçoamento de sua gestão tecnológica para o aproveitamento dos resultados de pesquisa acadêmica (GARNICA; OLIVEIRA; TORKOMIAN, 2006). Essa adequação se refere ao estabelecimento de regulamentações internas e também no que se refere à implementação de uma infraestrutura capaz de proteger e comercializar tecnologias universitárias valendo-se de ferramentas de gestão e capacitação requeridas para tais atividades.

Diante deste desafio, visto que a literatura especializada tem indicado a importância de uma análise detalhada e profunda de um número maior de casos e as dificuldades específicas enfrentadas pelas universidades no processo de licenciamento de patentes para empresas (STAL; FUJINO, 2002), a questão motivadora desta pesquisa referiu-se ao desejo de melhor compreender como as universidades estão conduzindo processos envolvendo propriedade intelectual e transferência de tecnologia, quais as políticas vigentes que ditam sua gestão tecnológica e como se pode ilustrar a ocorrência de processos de transferência de tecnologia envolvendo o uso da propriedade intelectual.
Assim, o objetivo mais direto deste trabalho foi apresentar as diretrizes políticas e o desempenho das universidades públicas instaladas no Estado de São Paulo quanto ao patenteamento e à comercialização de tecnologias, identificando fatores de dificuldade e de apoio em processos específicos de transferência tecnológica para empresas.

$\mathrm{O}$ artigo segue estruturado em sua segunda seção com a explicitação da metodologia da pesquisa. As seções 3,4 e 5 fundamentam teoricamente o trabalho com elementos conceituais e a experiência internacional em patenteamento e transferência de tecnologia. A apresentação dos resultados é feita na seção 6 abordando uma síntese do perfil das universidades objeto do estudo e de suas diretrizes em propriedade intelectual, o desempenho em patenteamento de cada uma delas e o estudo de contratos de transferência de tecnologia concluindo com os desafios percebidos na implementação dessas parcerias. Na seção 7 , são feitas considerações finais sobre a pesquisa e apresentados indicativos para futuros estudos.

\section{Aspectos metodológicos da pesquisa}

Uma vez que não há uma ampla gama de estudos preliminares com o escopo estrito deste trabalho sobre o tema da pesquisa, o estudo possui caráter exploratório, além de características de um estudo descritivo. Foram seguidos os pressupostos do método qualitativo objetivando compreender fatos em profundidade. O delineamento da pesquisa é de múltiplos casos com foco no entendimento da dinâmica presente de fatos recentes (EISNHARDT, 1989) e em fenômenos contemporâneos inseridos em um contexto da vida real em que o pesquisador não tem domínio das variáveis (YIN, 2001).

Para o estudo multicaso, foram utilizados instrumentos diversos de coleta de dados, já que pesquisas qualitativas são caracteristicamente multimetodológicas (ALVES-MAZZOTTI; GEWANDSZNAJDER, 1998). O estudo multicaso se refere a cinco universidades públicas estudadas, tendo sido tomado em cada uma delas um contrato específico para análise em profundidade, com o propósito de ilustrar o processo de transferência de tecnologia conduzido em cada uma das instituições. A escolha do contrato foi orientada para fatos jurídico-administrativos mais consolidados nas instituições, devido à maior possibilidade de obtenção de informações.

As universidades selecionadas foram: Universidade de São Paulo (USP), Universidade Estadual Paulista (Unesp), Universidade Estadual de Campinas (Unicamp), Universidade Federal de São Paulo (Unifesp) e Universidade Federal de São Carlos (UFSCar). A escolha delas remete ao propósito de realizar uma investigação em todas as universidades públicas instaladas no Estado de São Paulo, com exceção da Universidade Federal do ABC (UFABC) recém-criada. Ainda, tal escolha foi devida ao reconhecido prestígio no 
meio acadêmico, fundamentado na intensa atividade de pesquisa dessas universidades.

Foram coletados dados primários e secundários dos três grupos de agentes envolvidos nos processos estudados, isto é, de pesquisadores, de gestores de propriedade intelectual nas universidades e de responsáveis nas empresas parceiras.

Para assegurar uma adequada coleta de dados e permitir a estruturação de análises, foram utilizados nas entrevistas três roteiros semiestruturados diferentes entre os grupos de entrevistados, tendo como principais variáveis com foco na universidade: i) interesses de pesquisadores por determinada área de pesquisa; ii) obtenção de financiamento e parcerias na pesquisa; iii) conhecimento sobre propriedade intelectual; e iv) questões processuais de dificuldade, apoio e sugestões de aperfeiçoamento para futuros processos. No âmbito dos NIT, enfatizou-se: i) a institucionalidade da gestão de propriedade intelectual e transferência de tecnologia; ii) a organização e infraestrutura voltada a essa gestão; iii) implementação de atividades pró-inovação; e iv) práticas de gestão e questões processuais de dificuldade, apoio e sugestões de melhoria em transferência de tecnologia. Para as empresas, destacaram-se as variáveis: i) perfil da empresa e mercados de atuação; ii) cooperação com instituições externas e expectativas inerentes; iii) motivações para a internalização de tecnologias da universidade; e iv) percepção empresarial de fatores de dificuldade, apoio e sugestões de aperfeiçoamento na cooperação interinstitucional. O período de realização da pesquisa de campo compreendeu os meses de setembro/2006 a maio/2007 totalizando 18 entrevistas.

\section{A universidade como geradora de tecnologia: breve histórico e contexto institucional}

Inicialmente, cumpre destacar que a preocupação com a gestão tecnológica no contexto acadêmico está diretamente relacionada à etapa subsequente à atividade de pesquisa que resulta em novos conhecimentos passíveis de se transformarem em tecnologias comercializáveis.

Uma abordagem possível sobre a visão da universidade enquanto organização de C\&T se refere ao conceito de universidade empreendedora, no qual a universidade capaz de cooperar com empresas e demais instituições da sociedade não tem como única função a formação de pessoal qualificado, mas a função de pesquisa e de extensão no sentido amplo de viabilizar formas de apoiar o desenvolvimento econômico. Na figura 1, Etzkowitz (2004) esboça o processo em que a universidade passou a desenvolver uma característica empreendedora.

Ainda na Idade Média, a universidade visava apenas à atividade de ensino, transmitindo o conhecimento já gerado. No final do século XIX, grande parte das instituições acadêmicas passou a enfatizar a interconectividade entre o ensino e a pesquisa, resultando na denominada "Primeira
Revolução Acadêmica". Como geradoras de conhecimento, as universidades passaram a ser objeto de interesse de aproximação para o setor produtivo, ao mesmo tempo em que a maioria dos fundos públicos de pesquisa destinados a universidades nos EUA se tornou escassa. Isso levou a uma busca por parte dos acadêmicos para complementar recursos para pesquisas por meio da interação com o capital privado (ETZKOWITZ, 2004).

Somou-se a esse interesse dos acadêmicos em obter mais recursos para pesquisas, o fato de que novos conhecimentos técnico-científicos de aplicação industrial começaram, por um processo de transbordamento (spill-over) das atividades de pesquisa, a resultar em novas empresas de base tecnológica.

Nesse contexto, o estabelecimento de políticas de gestão tecnológica do setor acadêmico tornou-se imprescindível para assegurar os interesses de ambas as partes e permitir uma maximização do uso das tecnologias geradas, procurando ao mesmo tempo minimizar conflitos. Os dois principais aspectos que compõem a política de uma universidade quanto à sua gestão tecnológica se referem à proteção intelectual de tecnologias para fins de apropriabilidade pela universidade e sua transferência a setores que possam implementá-la.

Como parte do contexto institucional, cumpre dizer que foram criadas estruturas organizacionais dentro das universidades ou mesmo associadas a elas para gerenciar



Figura 1. Coevolução e multilinearidade das relações universidadeindústria. Fonte: Adaptado de Etzkowitz (2004) (tradução dos autores). 
a propriedade intelectual e a transferência de tecnologia. Isso, devido ao alto grau de especificidade e complexidade exigidas no processo colaborativo universidade e empresa, no qual se verificam barreiras à sua cooperação, sendo algumas delas a extensão do tempo de projetos, grau de incerteza, a pesquisa fundamental da universidade, diferentes filosofias de administração das organizações e excesso de burocracia nas estruturas acadêmicas (SEGATTO-MENDES; SBRAGIA, 2002).

Em países com relevante papel do setor governamental na promoção do desenvolvimento econômico e social, em particular no tocante a políticas indutivas de colaboração entre os atores do sistema de inovação, incluindo instituições de pesquisa e o setor empresarial, observou-se a regulamentação de medidas de incentivo à criação de um ambiente propício à inovação. No Brasil, a Lei de Inovação Federal de 2004 foi sancionada como resultado de um processo iniciado em 2001 por meio de um anteprojeto exposto na Conferência Nacional de Ciência e Tecnologia organizada pelo Ministério de Ciência e Tecnologia. Uma vez que os diferentes estados brasileiros também abrigam oportunidades particulares, além do fortalecimento da Lei no País, também têm sido estabelecidas Leis Estaduais de Inovação. No Estado de São Paulo, a disposição legal foi estabelecida a Lei Complementar 1.049 de 19 de junho de 2008 com destaque para a promoção de habitats de inovação, criando o Sistema Paulista de Parques Tecnológicos e para o fortalecimento de mecanismos de inovação com fundos públicos.

Com foco nas estruturas de apoio à proteção e à comercialização do conhecimento, a Lei de Inovação indicou a necessidade de que as instituições científicas e tecnológicas disponham de Núcleo de Inovação Tecnológica (NIT) (BRASIL, 2004) para contribuir na elaboração e gestão de suas políticas de inovação. Utilizando a terminologia "escritório de transferência de tecnologia -", bastante comum na literatura internacional e que pode ser utilizada de forma intercambiável neste trabalho, Terra (2001) explica que os ETT buscam contatos permanentes com empresas e governos locais, tendo intensificado sua atuação no contexto da formulação de políticas de planejamento de C\&T e interação universidade-empresa-governo. De fato, diferentes estruturas com diferentes nomes cumpriram as finalidades citadas acima nas universidades, mesmo antes do advento da Lei de Inovação. Atualmente, os nomes mais utilizados são "Agência de Inovação" ou "Núcleo de Inovação Tecnológica" tal como proposto na Lei e utilizado neste trabalho para menções ao caso brasileiro.

\section{Mecanismos de transferência de tecnologia universitária e 0 licenciamento de patentes}

A universidade transfere tecnologia ao meio externo de muitas formas, sendo a mais tradicional os profissionais que prepara e forma. Para Rogers, Takegami e Yin (2000), os principais mecanismos de transferência de tecnologia são:

- Spin-offs - a transferência de uma inovação tecnológica para um novo empreendimento constituído por um indivíduo oriundo de uma organização-mãe;

- Licenciamento - garantias de permissão ou uso de direitos de certo produto, desenho industrial ou processo;

- Publicações - artigos publicados em periódicos acadêmicos;

- Encontros - interação face a face, na qual uma informação técnica é trocada; e

- Projetos de P\&D cooperativos - acordos para compartilhamento de pessoas, equipamentos, direitos de propriedade intelectual, geralmente, entre institutos públicos de pesquisa e empresas privadas em uma pesquisa.

O contexto de cooperação envolvendo empresas e universidades para inovação está também ligado e se configura como fator instrumentalizador dentro da visão macro de gestão da inovação entendida como inovação aberta (open innovation). Essa perspectiva, enquanto conceito, prevê que o conhecimento está distribuído globalmente de modo a ser impossível para as empresas se assegurarem de sua competitividade baseada na inovação por meio único exclusivo do desenvolvimento interno. Esse conceito de inovação aberta está relacionado à possibilidade de utilização de caminhos internos e externos para avançar no desenvolvimento de novas tecnologias, contradizendo o modelo fechado de inovação, segundo o qual as empresas deveriam investir em grandes laboratórios de $\mathrm{P} \& \mathrm{D}$ voltando-se com força ao desenvolvimento próprio de tecnologias (CHESBROUGH, 2003).

Os principais mecanismos dentre os quais a universidade pode fazer uso no contexto de sua interação pró-inovação são de particular interesse para este estudo o licenciamento de patentes e os projetos de $\mathrm{P} \& \mathrm{D}$ cooperativos. No tocante ao licenciamento, cabe introduzir brevemente aspectos conceituais sobre a propriedade intelectual.

Os conceitos de propriedade são atribuídos mais facilmente a coisas que são tangíveis ante as intangíveis, dificultando com isso, o entendimento do que se trata a proteção de ideias, inventos, obras artísticas, etc. $\mathrm{O}$ valor econômico de tais bens, ou mesmo a expectativa deste, auxilia na compreensão do sentido da apropriação privada de produtos da mente humana. Di Blasi et al. (2000, p.15) explicam que:

a propriedade, em seu sentido lato, é o poder irrestrito de uma pessoa sobre um bem, sendo que a propriedade dos bens imateriais é regida por regras específicas as quais constituem o direito da propriedade intelectual.

Sendo a propriedade industrial um subgrupo de direitos de propriedade intelectual relativos a tecnologias de aplicação 
na indústria, a patente é parte dela, podendo ser definida pela World Intellectual Property Organization (WIPO) (2005) como um direito exclusivo garantido por uma invenção, na qual um produto ou um processo provê uma nova forma de fazer algo ou oferecer uma nova solução técnica para um problema.

Conforme Lei de Propriedade Industrial Brasileira $n^{\circ}$ 9.279/96 (Art.40), a patente de invenção possui prazo de validade de 20 anos e para modelo de utilidade 15 anos, tendo como principais finalidades para esse direito previsto, o estímulo ao investimento em $P \& D$ por meio da expectativa de retorno dos gastos efetuados e, por outro lado, um sistema que permite a publicação de dados técnicos de inventos com amplo acesso pela sociedade, propiciando a continuidade do desenvolvimento tecnológico de forma mais dinâmica e evitando o desperdício de recursos na obtenção de resultados já obtidos por outros desenvolvedores.

De acordo com suas finalidades, as universidades não patenteiam para si, mas buscam proteger, codificar o conhecimento e tornar a invenção viável economicamente (GRAFF; HEIMAN; ZILBERMAN, 2002), sendo que esta ênfase é o eixo estruturante do papel da propriedade intelectual para transferência de tecnologia universitária. Assim, a universidade pode conceder licenças de patente para empresas, apresentando as seguintes possíveis características: a) licença não exclusiva, com ou sem pagamento de royalties e incluindo ou excluindo direito de sublicenciamento; b) licença exclusiva, com pagamento de royalties, em área específica de exploração, podendo a empresa sublicenciar; c) licença exclusiva, com pagamento de royalties incluindo o direito de sublicenciar; e d) licença exclusiva, sem pagamento de royalties, incluindo direito de sublicenciar (SOUZA NETO; STAL 1998 apud CHAGAS, 2004).

\section{A experiência dos EUA e da Inglaterra e indicativos do caso brasileiro}

A experiência internacional mais avançada em gestão da propriedade intelectual e transferência de tecnologia é a dos EUA, na qual pode ser observada indução política pró-interação universidade-empresa. O sistema de propriedade intelectual do EUA foi aperfeiçoado para reduzir os riscos de investimentos em novas empresas de tecnologia ao mesmo tempo em que sucessivas legislações editadas aceleraram e difundiram a prática da transferência de tecnologia de laboratórios de pesquisa (LOCKETT et al., 2005). Ainda, a criação de um sistema federal de apoio à pesquisa nas universidades que conduziu à geração de conhecimento científico e tecnológico útil para o setor produtivo foi, possivelmente, o mais importante entre todos os estágios conduzidos para construção de um sistema de inovação maduro nos EUA (ETZKOWITZ; STEVENS, 1998).

A magnitude do patenteamento pelo setor acadêmico nos EUA, embora ainda pequena frente à indústria, tem crescido substancialmente nos últimos 20 anos. $\mathrm{O}$ número de universidades engajadas no licenciamento de tecnologias chegou a 200 e o volume de patentes quadruplicou (MOWERY; SHANE, 2002). Em 2000, as patentes acadêmicas representaram $2 \%$ do total, tendo saído de menos de 0,5\% em 1985. A Universidade da Califórnia liderava o ranking com 324 patentes concedidas apenas naquele ano, seguida do Massachusetts Institute of Technology (MIT) com 152.

O levantamento mais completo de dados dessa natureza é responsabilidade da Association of University Technology Managers (AUTM), criada especificamente para organizar dados e apoiar a gestão tecnológica de universidades dos EUA e Canadá. Em 2004, participaram de um survey mais de 381 instituições, sendo 232 universidades. Foram introduzidos, desde 1998 até 2004, 3.114 novos produtos no mercado de 185 instituições diferentes, tendo sido depositados neste ano 10.517 pedidos de patentes de 184 instituições (AUTM, 2005).

Quanto às licenças para exploração de patentes, foram 4.783 em 2004. Houve exclusividade nos direitos de exploração para empresas em $34,7 \%$ dos casos. Entre as pequenas empresas, esse percentual chegou a $42,1 \%$ e $90,9 \%$ quando se trata de novas empresas criadas para comercializar o invento. O retorno econômico do licenciamento de tecnologia, mesmo sendo ainda tímido, se considerado o orçamento global das universidades, cresceu mais de 500\%, saindo de menos de 200 milhões em 1991 para mais de US\$ 1,2 bilhão em 2000. Os campos tecnológicos mais recorrentes nesta prática foram a medicina ( $46 \%$ das patentes licenciadas e $55 \%$ dos rendimentos de licenças), seguida da engenharia e da física com 34 e $24 \%$ das patentes licenciadas, respectivamente (GRAFF; HEIMAN; ZILBERMAN, 2002).

Visto que não é necessário aguardar a concessão de uma patente para comercializá-la, observa-se que $72 \%$ dos licenciamentos de patente para empresas nos EUA ocorrem em fase de depósito. A iniciativa para acordos de licenciamento de tecnologias nos EUA costuma partir de um contato do inventor com alguma empresa ou pessoa-chave; isto ocorre em 56\% dos casos. Os esforços de marketing e a prospecção de negócios do ETT representam 19\% dos casos. Finalmente, em apenas 10\% dos casos as empresas buscam as universidades para licenciar suas patentes (GRAFF; HEIMAN; ZILBERMAN, 2002).

$\mathrm{Na}$ Inglaterra, nota-se que as universidades, em sua maioria, públicas têm testemunhado mudanças substanciais em termos de objetivos de pesquisa e fontes de financiamento. A variedade de fundos de investimento em pesquisa está aumentando ao passo que o orçamento público encolheu dadas as restrições orçamentárias (GEUNA; NESTA, 2003).

A atividade de patenteamento universitário cresceu na Inglaterra a partir dos anos 1980. Dados levantados de 13 
países da Europa revelam que a Inglaterra era o país com maior número de patentes de universidades depositadas até 2002. No último quadriênio ela foi responsável por 915 de 1.782 patentes levantadas no total dos países. Na Inglaterra, as patentes depositadas por universidades frente ao número global de patentes depositadas demonstram que em 1997 elas representavam 1\%, porém, no período 1998-2002, já eram 3\% do total. Quanto às inter-relações dessas universidades, observadas por meio dos depósitos de patentes feitos em conjunto, isto é, em cotitularidade, a Inglaterra demonstra maior tradição frente a outros países europeus (RUIZ, 2005).

Considerando o Reino Unido, o primeiro survey realizado sobre comercialização nas universidades foi realizado pela University Companies Association (UNICO). Em pesquisa realizada em 2001, com uma amostra de $85 \%$ de respondentes, observou-se que, 77 universidades desenvolveram 1.402 invenções, 743 depósitos de patentes e 276 patentes concedidas. Como retorno desse estoque, $60 \%$ das universidades receberam menos que 50.000 libras de licenças e $40 \%$ não receberam rendimentos. Para $68 \%$ das instituições, gastos na gestão da propriedade intelectual foram menores que essa receita média, no entanto, $14 \%$ não gastaram nisto. Uma conclusão rápida desses dados é que os EUA e o Canadá estão à frente do Reino Unido em termos de rendimentos de licenças e em número de patentes depositadas e concedidas (GEUNA; NESTA, 2003).

A pesquisa de Chapple et al. (2005) envolvendo o contexto inglês apontou que a baixa remuneração aos inventores universitários representa um dos obstáculos à transferência de tecnologia. Outro fator problemático é que a eficiência da transferência de tecnologia varia em função do tamanho da universidade e das áreas da ciência abarcadas por esta. ETT, que precisam lidar com muitas áreas diferentes, costumam possuir um índice menor de eficiência. Além disso, não se observam economias de escala nesse tipo de atividade, indicando que ETT menores e mais especializados podem ser mais eficientes.

No Brasil, a prática da transferência de tecnologia formal entre universidades e empresas brasileiras, especialmente fazendo uso da propriedade intelectual, é bastante recente, de modo que não há dados nacionais representativos ou mesmo uma prática desenvolvida na área que possa indicar seguramente a maturidade de processos dessa natureza, sendo que algumas universidades e instituições de pesquisa criaram mecanismos institucionais de gestão da propriedade intelectual e da transferência de tecnologia mesmo antes da Lei de Inovação 2004, dentre elas, a EMBRAPA, FIOCRUZ, UFSCar, UFRJ, USP, Unicamp e UFMG (SCHOLZE; CHAMAS, 2000) e, em alguns casos, órgãos internos à universidade ou em convênio com esta cumprem esse papel.

Mais amplamente, foi promovido um survey nacional sobre núcleos de inovação, o qual demonstrou que nas universidades que mantêm núcleos de propriedade intelectual, nem sempre eles cumprem com sua finalidade na prática (UFRGS, 2002). Essa é uma decorrência do histórico desconhecimento do valor e da importância do sistema patentário, bem como do envolvimento das universidades com outras prioridades. Possivelmente já havia tecnologias oriundas de pesquisas universitárias antes que fossem depositados os primeiros pedidos de patente pelas universidades, no entanto, parte delas era protegida em nome de empresas envolvidas com os projetos de pesquisa ou dos próprios inventores.

Em geral, a coleta de dados sobre o número de patentes universitárias depositadas e concedidas mostra-se ainda difícil. Há, não raras vezes, discordâncias entre diferentes

Tabela 1. Perfil das universidades objeto do estudo. Fonte: Sites das universidades (www.usp.br; www.unesp.br; www.unicamp.br; www.unifesp.br; www.ufscar.br).

\begin{tabular}{|c|c|c|c|c|c|}
\hline \multirow[b]{2}{*}{ Caracterização } & \multicolumn{5}{|c|}{ Universidades objeto do estudo } \\
\hline & $\begin{array}{c}\text { USP } \\
(\text { dados 2005) }\end{array}$ & $\begin{array}{c}\text { Unesp } \\
(\text { dados 2006) }\end{array}$ & $\begin{array}{c}\text { Unicamp } \\
(\text { dados 2006) }\end{array}$ & $\begin{array}{c}\text { Unifesp } \\
(\text { dados 2004) } \\
\end{array}$ & $\begin{array}{c}\text { UFSCar } \\
(\text { dados 2005) }\end{array}$ \\
\hline Ano de criação & 1934 & 1976 & 1966 & $\begin{array}{c}1994 \\
(1933-\mathrm{EPM})\end{array}$ & 1968 \\
\hline Natureza jurídica & $\begin{array}{c}\text { Instituição } \\
\text { pública estadual }\end{array}$ & $\begin{array}{c}\text { Instituição } \\
\text { pública estadual }\end{array}$ & $\begin{array}{c}\text { Instituição } \\
\text { pública estadual }\end{array}$ & $\begin{array}{l}\text { Instituição } \\
\text { pública federal }\end{array}$ & $\begin{array}{c}\text { Instituição } \\
\text { pública federal }\end{array}$ \\
\hline $\mathrm{n}^{\circ}$ alunos & 80.589 & 46.353 & 43.006 & 2.755 & 7500 \\
\hline $\mathrm{n}^{\mathrm{o}}$ docentes & 5.222 & 3.507 & 2.125 & 626 & 558 \\
\hline Artigos científicos & $\begin{array}{c}5.265 \\
\text { Indexados ISI* }\end{array}$ & $\begin{array}{c}1.109 \\
\text { Indexados ISI* }\end{array}$ & $\begin{array}{c}2.112 \\
\text { Indexados ISI* }\end{array}$ & $\begin{array}{c}688 \\
\text { Citações SCI** }\end{array}$ & $\begin{array}{c}514 \\
\text { Citações SCI** }\end{array}$ \\
\hline $\begin{array}{l}\text { Número de Grupos de Pesquisa e } \\
\text { representação no total de grupos*** }\end{array}$ & $\begin{array}{c}1780 \\
(8,5 \%) \\
\end{array}$ & $\begin{array}{c}774 \\
(3,7 \%) \\
\end{array}$ & $\begin{array}{c}628 \\
(3 \%) \\
\end{array}$ & $\begin{array}{c}204 \\
(1 \%) \\
\end{array}$ & $\begin{array}{c}277 \\
(1,3 \%) \\
\end{array}$ \\
\hline
\end{tabular}


estudos que tratam desses dados. $\mathrm{O}$ volume de patenteamento pelas universidades é relativamente pequeno, mas pode-se observar uma tendência de crescimento. Comparando o total de depósitos de pedidos de patentes no INPI em 2001, revela-se que 5\% dessas aplicações procedem do meio acadêmico (HAASE; ARAÚJO; DIAS, 2005).

\section{Apresentação dos resultados}

\subsection{Perfil das universidades públicas no Estado de São Paulo}

A identificação do perfil básico das universidades objeto de estudo, conforme pode ser observado na tabela 1, é relevante especialmente se visto como fonte de informação contextual e também como indicativo do esforço de pesquisa enquanto dados de entrada (input), permitindo a relativização entre as instituições. Em particular, a análise de desempenho em patenteamento pelas instituições pode considerar, entre outros fatores, o número de pesquisadores dedicados e o volume de trabalhos científicos publicados e indexados em bases de alto prestígio no meio acadêmiCo internacional, bem como o número de grupos de pesquisa cadastrados no Diretório do Grupo de Pesquisas do CNPq referentes a cada uma das instituições no ano de realização da pesquisa.

\subsection{As políticas de propriedade intelectual das universidades: breve contexto}

A normatização da propriedade intelectual nas universidades se dá por meio do estabelecimento de Portarias e Resoluções que expressam as diretrizes políticas institucionais. Especialmente por se tratarem de entes públicos, ao exercerem suas atividades, as universidades devem estar amparadas em suas normas legais e praticá-las por meio de atos administrativos. Essas diretrizes são muito importantes para as atividades de transferência de tecnologia, pois elas determinam em grande parte qual ativo intelectual e de que forma o conhecimento acadêmico pode ser comercializado.

Conforme pode ser visto na tabela 2, a USP e Unicamp apresentaram ações na área de propriedade intelectual ainda na década de 1980, sendo que em ambas a vinculação institucional do NIT é com a Reitoria da Universidade. No caso da USP, observa-se uma norma restrita a patentes, não tendo sido atualizada até o momento. Disto, vale dizer que, embora conste nas normas de cada uma das universidades apenas a abrangência indicada, tem sido uma prática comum a proteção de outros tipos de propriedade intelectual de forma análoga ao estabelecido na norma, permitindo uma proteção e apropriabilidade mais ampla do que é produzido na universidade.

$\mathrm{O}$ ano da primeira norma existente nas universidades reflete o momento em que a preocupação com o tema da propriedade intelectual foi revelado no marco regulatório institucional, não implicando necessariamente na criação de uma estrutura. Quanto ao processo de institucionalização das estruturas organizacionais de gestão da propriedade intelectual, verifica-se sua ocorrência mesmo antes da Lei de Inovação, cabendo às universidades a indicação formal de que tais estruturas correspondem ao NIT, conforme indicado na Lei, com suas devidas incumbências.

\subsection{Desempenho em patenteamento e comercialização nas universidades}

As atividades de patenteamento em universidades públicas no Brasil são recentes, especialmente em se tratando de comparar com a experiência dos EUA. Mesmo as universidades brasileiras que iniciaram a organização pioneiramente aos dispositivos legais vigentes, não alcançaram grandes avanços em termos de volume de tecnologias protegidas e nem de sua transferência para empresas.

Tabela 2. Normatização e estrutura para gestão da propriedade intelectual nas universidades estudadas.

\begin{tabular}{|c|c|c|c|c|c|c|}
\hline $\begin{array}{c}\text { Nome da } \\
\text { universidade }\end{array}$ & $\begin{array}{c}\text { Ano da } \\
\text { 1a. Norma }^{\text {a }}\end{array}$ & $\begin{array}{l}\text { Ano da constituição } \\
\text { formal do NIT }\end{array}$ & $\begin{array}{c}\text { Norma } \\
\text { vigente/ano }\end{array}$ & Abrangência & Nome do nit atual & $\begin{array}{c}\text { Vinculação } \\
\text { institucional }\end{array}$ \\
\hline USP & 1988 & 2005 & $\begin{array}{c}\text { Resolução } \\
3.428 / 1988\end{array}$ & Patentes & $\begin{array}{l}\text { Agência USP de } \\
\text { Inovação }\end{array}$ & Reitoria \\
\hline Unesp & 2000 & 2007 & $\begin{array}{c}\text { Portaria } n^{\circ} \\
424 / 2006\end{array}$ & $\begin{array}{l}\text { Propriedade } \\
\text { Industrial }\end{array}$ & $\begin{array}{l}\text { NIT-Unesp } \\
\text { (não definido) }\end{array}$ & $\begin{array}{c}\text { Pró-Reitoria de } \\
\text { Pesquisa }\end{array}$ \\
\hline Unicamp & 1984 & 2003 & $\begin{array}{c}\text { Deliberação } \\
\text { Consu A2 /2002 }\end{array}$ & $\begin{array}{c}\text { Prop. industrial, } \\
\text { software e cultivares }\end{array}$ & INOVA - UNICAMP & Reitoria \\
\hline Unifesp & 2000 & 2002 & $\begin{array}{l}\text { Portaria }{ }^{\circ} \\
662 / 2002\end{array}$ & $\begin{array}{l}\text { Propriedade } \\
\text { Intelectual }\end{array}$ & $\begin{array}{l}\text { Núcleo de Propriedade } \\
\text { Intelectual - NUPI }\end{array}$ & $\begin{array}{l}\text { Pró-Reitoria de } \\
\text { Administração }\end{array}$ \\
\hline UFSCar & 2003 & 2007 & $\begin{array}{c}\text { Portaria GR n }{ }^{\circ} \\
627 / 2003\end{array}$ & $\begin{array}{l}\text { Propriedade } \\
\text { Intelectual }\end{array}$ & $\begin{array}{l}\text { FAI-UFSCar - Divisão } \\
\text { de Propriedade } \\
\text { Intelectual }\end{array}$ & $\begin{array}{c}\text { Reitoria } \\
\text { (Convênio } \\
\text { UFSCar/FAI) }\end{array}$ \\
\hline
\end{tabular}

Fonte: Dados da pesquisa. 
Observando dados de anos anteriores a 1999, apenas a USP e a Unicamp com 17 e 10, respectivamente, tiveram na linha histórica, com maior expressividade, pedidos depositados em 1989. Deste período anterior, não se tem relato sobre o licenciamento de tecnologia ou exploração dessas patentes. Entretanto, considerando os últimos 5 anos, observa-se um crescimento da tendência ao patenteamento, sendo que os totais acumulados do período indicados no Figura 2 foram: Unicamp 371; USP 166; Unesp 57; UFSCar 30 e Unifesp 29.

O processamento da gestão da propriedade intelectual nessas universidades vem sofrendo constantes alterações, tendo em vista a formatação de novos arranjos organizacionais que atendam às demandas de proteção e transferência tecnológica. Atualmente, todas as instituições permitem a cotitularidade em patentes, isto é, o compartilhamento desses ativos com empresas ou outras instituições de C\&T.

Quanto ao custeio do patenteamento, apenas a USP regulamenta o pagamento de $50 \%$ pelos inventores, sendo que as demais universidades custeiam integralmente o pedido nacional. No contexto internacional este custeio é feito, predominantemente, pelas instituições empregadoras.

Tendo em vista a importância da exploração de tecnologia em perspectiva global, verificou-se que as universidades não realizam proteção internacional com recursos próprios devido ao alto de custo que atinge a média de $\mathrm{R} \$ 100 \mathrm{mil}$, considerando os maiores mercados mundiais. Essa proteção é feita apenas com suporte de agências de fomento ou de empresas parceiras coproprietárias ou licenciadas nos direitos de patente.

As atividades diretamente relacionadas ao patenteamento pelas universidades podem assumir uma maior ou menor terceirização dependendo da estrutura do NIT e da política da universidade para essa gestão. Em geral, a redação de patentes é terceirizada, pois carece de profissionais muito especializados em diversas áreas do conhecimento e com regularidade inconstante de trabalho. Isso faz com que seja viável a contratação particularizada caso a caso de escritórios de propriedade intelectual ou de redatores profissionais de patentes. Em 4 casos, foi observado o uso da terceirização para esta tarefa, sendo que na Unesp esta questão está em análise e deverá ser definida pela terceirização desses serviços, segundo o entrevistado.

\subsubsection{Transferência de tecnologia nas universidades}

Todas as universidades estão voltadas às atividades de transferência de tecnologia, de modo que ela é permitida e reconhecida por seus órgãos superiores. Vale ressaltar que cada instituição possui um perfil, sendo muito semelhantes os casos da USP, Unesp, Unicamp e UFSCar no tocante às áreas de atuação, tipos de proteção intelectual e mecanismos formais de transferência de tecnologia. Em particular, a Unifesp desenvolve pesquisas na área médica envolvendo desenvolvimento de fármacos, tendo sido possível notar um uso mais comum de parcerias para desenvolvimento conjunto com empresas ao invés do licenciamento direto de patentes resultantes exclusivamente da pesquisa da universidade. Esta é uma peculiaridade do processo de pesquisa na área de medicamentos, de acordo com o averiguado nesta pesquisa.

Quanto à distribuição dos proventos econômicos oriundos da transferência de tecnologia nas universidades, observa-se um padrão em torno de $1 / 3$ para o(s) inventor(es) a título de prêmio, com exceção da USP que repassa $50 \%$ dos proventos. Isso porque, no caso desta universidade, a prerrogativa é a divisão em partes iguais dos custos e benefícios, de acordo com a Resolução 3.428/88. Em

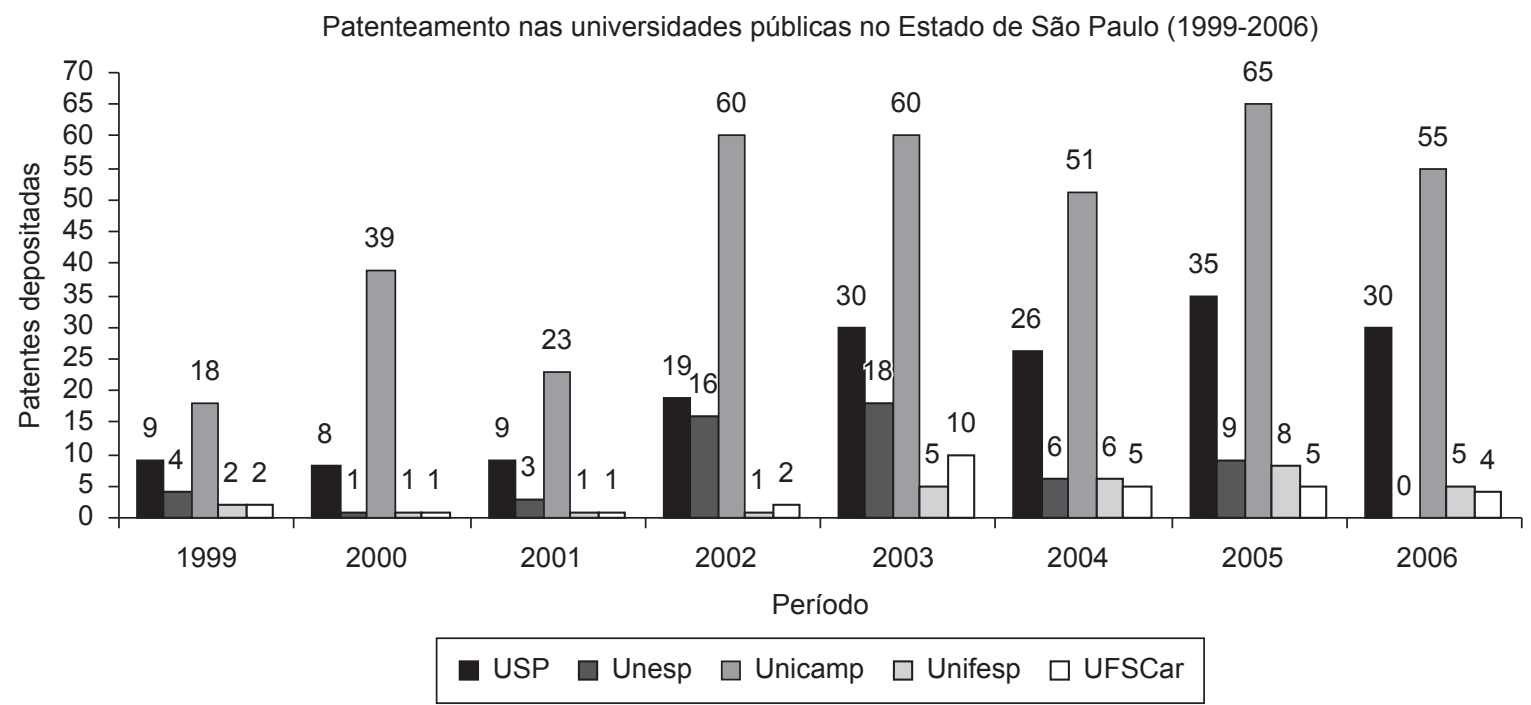

Figura 2. Patenteamento nas universidades públicas no Estado de São Paulo (1999-2006). Fonte: Dados da pesquisa junto às universidades. 
geral, no que se refere à divisão dos recursos destinados à universidade se prevê sua aplicação no departamento de origem do inventor e em sua respectiva unidade acadêmica, havendo sempre um percentual destinado à administração da universidade.

Em busca de informações que evidenciassem o uso de patentes ou de diretrizes contratuais de propriedade intelectual em contratos de transferência de tecnologia, podendo ser de licenciamento de patentes ou de desenvolvimentos conjuntos empresa e universidade, foi afirmado pela totalidade dos entrevistados que a patente ou a previsão de uma propriedade intelectual em contratos dessa natureza exerce um papel importante. Os principais aspectos levantados foram:

- a garantia de que os resultados do esforço de P\&D da universidade sejam valorizados e definidos de modo a possibilitar uma política para seu uso e exploração;

- a patente assegura e delimita com força legal a tecnologia desenvolvida e seus responsáveis, possibilitando mais uma forma de reconhecimento da contribuição da universidade em projetos tecnológicos; e

- a patente permite a divulgação e, ao mesmo tempo, a parceria direta com empresas que poderão ter preferência na exploração da tecnologia por terem investido na pesquisa.

\subsection{Análise dos contratos de transferência de tecnologia identificados}

Tendo sido selecionado um contrato de transferência de tecnologia de cada universidade para exame aprofundado e, em consonância com o relato de entrevistados que participaram do processo envolvendo universidade e empresa, a Tabela 3 apresenta os principais itens estruturais e práticos envolvidos nos processos de transferência de tecnologia.

Foi possível observar 3 ocorrências tratando de contratos de licenciamento de patente com exclusividade, mas apenas uma empresa é selecionada para explorar a tecnologia.
Na USP e UFSCar, foram patentes tendo como única titular a universidade e na Unicamp a tecnologia havia sido desenvolvida em parceria e tinha a empresa como coproprietária da patente. Na Unesp e Unifesp, tratou-se de desenvolvimentos conjuntos, sendo que os contratos dispunham sobre propriedade intelectual, uso de possíveis resultados do projeto, valendo ressaltar que o contrato da Unesp prevê pagamento de royalties inclusive de produtos não patenteados que sejam resultantes da parceria com a universidade. Esse foi um grande avanço verificado na valorização do conhecimento da universidade, mesmo em caso de objeto não patenteável.

O grau de maturidade da tecnologia foi entendido como uma resultante da análise técnica de viabilidade para que a tecnologia esteja disponível como produto ou já incorporada a um produto final. Neste sentido, foi verificado em 3 casos o grau avançado, no qual a empresa apenas necessitará implementar escala industrial. Como grau acabado, no qual a empresa necessita apenas incorporar a tecnologia em sua forma técnica existente foi verificado 1 caso. Para o grau intermediário, definido pela necessidade de mais esforço de P\&D ainda em escala laboratorial, foi verificado 1 caso. Cabe ressaltar que esse indicativo foi dado pela percepção dos implementadores da tecnologia, considerando, em especial, o estágio de pesquisa e não a colocação do produto no mercado envolvendo ações de marketing. Quanto à iniciativa para a parceria, notaram-se 3 possibilidades. Uma em que a empresa identifica a tecnologia e solicita o licenciamento à universidade. Outra em que a universidade oferece a tecnologia para desenvolvimento e exploração para empresa. E uma terceira em que ambas as instituições, universidade e empresa, já desenvolvem em conjunto a tecnologia e, portanto, o processo de transferência de tecnologia é constante, também da empresa para a universidade.

Os percentuais de royalties definidos, os quais se referem à remuneração paga pela empresa licenciada à

Tabela 3. Comparativo das características dos contratos de transferência de tecnologia das universidades.

\begin{tabular}{|c|c|c|c|c|c|c|}
\hline $\begin{array}{l}\text { Tecnologia } \\
\text { de origem }\end{array}$ & $\begin{array}{l}\text { Existência } \\
\text { de PI } \\
\text { precedente }\end{array}$ & $\begin{array}{c}\text { Tipo } \\
\text { de contrato }\end{array}$ & $\begin{array}{c}\text { Contrato } \\
\text { regula futura } \\
\text { PI } \\
\end{array}$ & $\begin{array}{c}\text { Grau de } \\
\text { maturidade da } \\
\text { tecnologia } \\
\end{array}$ & $\begin{array}{l}\text { Percentual } \\
\text { de royalty }\end{array}$ & $\begin{array}{c}\text { Pro-atividade } \\
\text { inicial para } \\
\text { cooperação } \\
\end{array}$ \\
\hline USP & Sim & Licenciamento exclusivo & Não se aplica & Avançado & Não informado & Empresa \\
\hline Unesp & Não & Cooperação técnica & Sim & Avançado & $\begin{array}{l}4 \% \text { sobre } \\
\text { Faturamento bruto }\end{array}$ & Empresa \\
\hline Unicamp & Sim & Licenciamento exclusivo & Sim & Avançado & $\begin{array}{l}1,5 \% \text { sobre } \\
\text { faturamento bruto }\end{array}$ & $\begin{array}{c}\text { Conjunta } \\
\text { (cotitulares) }\end{array}$ \\
\hline Unifesp & Sim & $\mathrm{P} \& \mathrm{D}$ conjunto & Sim & Acabado & $\begin{array}{l}* \text { Entre } 4 \% \text { e } 6 \% \text { sobre } \\
\text { o faturamento líquido }\end{array}$ & $\begin{array}{l}\text { Universidade } \\
\text { (NIT) }\end{array}$ \\
\hline UFSCar & Sim & Licenciamento exclusivo & Sim & $\begin{array}{l}\text { Intermediário - } \\
\text { Avançado }\end{array}$ & $\begin{array}{l}3 \% \text { sobre } \\
\text { faturamento líquido }\end{array}$ & $\begin{array}{l}\text { Universidade } \\
\text { (inventor) }\end{array}$ \\
\hline
\end{tabular}

*A indicação de uma faixa entre $4 \%$ e $6 \%$ é uma estratégia de sigilo utilizada pela empresa, que não deseja especificar o exato percentual. Fonte: Dados da pesquisa. 
Quadro 1. Sistematização dos principais fatores de dificuldade e de apoio observados nos processos de transferência de tecnologia. Fonte: Dados da pesquisa.

\begin{tabular}{|c|c|c|}
\hline $\begin{array}{l}\text { Universidade/ } \\
\text { empresa }\end{array}$ & Fatores de dificuldade & Fatores de apoio/estímulo \\
\hline $\begin{array}{l}\text { USP/ } \\
\text { Empresa A }\end{array}$ & $\begin{array}{l}\text { - Modelo "fechado" de comercialização da } \\
\text { tecnologia (uso de licitação à época); } \\
\text { - Definição de royalties e valoração tecnológica; } \\
\text { - Burocracia excessiva na universidade; } \\
\text { - Morosidade do processo jurídico-administrativo } \\
\text { na universidade. }\end{array}$ & $\begin{array}{l}\text { - Existência de escritório especializado na } \\
\text { universidade para proteção e TT*; } \\
\text { - Remuneração pecuniária da TT* para a universidade } \\
\text { e inventor; } \\
\text { - Alta qualidade da tecnologia e do documento. de } \\
\text { patente. }\end{array}$ \\
\hline $\begin{array}{l}\text { Unesp/ } \\
\text { Empresa B }\end{array}$ & $\begin{array}{l}\text { - Pouco conhecimento técnico sobre } \\
\text { escalonamento da tecnologia; } \\
\text { - Morosidade da área jurídico-administrativa da } \\
\text { universidade; } \\
\text { - Acompanhamento e comunicação do processo } \\
\text { junto à empresa pouco sistemático. }\end{array}$ & $\begin{array}{l}\text { - Retorno financeiro para o inventor e para a } \\
\text { universidade; } \\
\text { - Confiança da empresa no inventor; } \\
\text { - Tecnologia ter sido testada, comprovada e de alta } \\
\text { expectativa de retorno financeiro; } \\
\text { - Suporte jurídico-administrativo da universidade. }\end{array}$ \\
\hline $\begin{array}{l}\text { Unicamp/ } \\
\text { Empresa C }\end{array}$ & $\begin{array}{l}\text { - Morosidade da área jurídico-administrativa da } \\
\text { universidade; } \\
\text { - Pouca flexibilidade na gestão do contrato e } \\
\text { dificuldade em suprir demandas emergentes da } \\
\text { parceira; } \\
\text { - Negociação do contrato de natureza } \\
\text { internacional, uso do inglês-jurídico e } \\
\text { necessidade de conciliar legislações nacionais. }\end{array}$ & $\begin{array}{l}\text { - Contratação de empresas especializadas na gestão } \\
\text { das patentes e dos projetos de P\&D pela Empresa } C \text {; } \\
\text { - Apoio e experiência do NIT para negociação e } \\
\text { trâmite do contrato na universidade; } \\
\text { - Pré-relacionamento entre as partes. Existência de } \\
\text { convênio/contrato anterior; } \\
\text { - Alta qualidade e expectativa de retorno financeiro } \\
\text { sobre a tecnologia; } \\
\text { - Uso de instrumentos formais para promoção da } \\
\text { segurança jurídica. }\end{array}$ \\
\hline $\begin{array}{l}\text { Unifesp/ } \\
\text { Empresa D }\end{array}$ & $\begin{array}{l}\text { - Carência de recursos humanos para } \\
\text { desenvolvimento da pesquisa; } \\
\text { - Tempo dedicado à interação entre inventor e } \\
\text { empresa poderia ser maior; } \\
\text { - Morosidade administrativa da universidade } \\
\text { resultando em prazo estendido para assinatura } \\
\text { de contrato; } \\
\text { - Gestão de projetos em pesquisa clínica } \\
\text { necessita de melhorias. }\end{array}$ & $\begin{array}{l}\text { - Apoio do NIT para: monitoramento de } \\
\text { oportunidades de TT*; conseguir parceiro; } \\
\text { negociar o contrato; e encaminhá-lo internamente à } \\
\text { universidade; } \\
\text { - Aprendizado do processo de P\&D conjunto com } \\
\text { empresas; } \\
\text { - Credibilidade da instituição acadêmica como } \\
\text { estímulo à qualidade da pesquisa e para negociação } \\
\text { com a indústria farmacêutica. }\end{array}$ \\
\hline $\begin{array}{l}\text { UFSCar/ } \\
\text { Empresa E }\end{array}$ & $\begin{array}{l}\text { - Morosidade no trâmite universitário em função } \\
\text { da burocracia excessiva; } \\
\text { - Fixação de percentual de royalties a serem } \\
\text { pagos pela empresa. Valoração tecnológica; } \\
\text { - Cultura de comercialização de tecnologia } \\
\text { universitária pouco desenvolvida; } \\
\text { - Custo da parceria com a universidade em } \\
\text { função da cobrança de taxas para efetivação de } \\
\text { contratos. }\end{array}$ & $\begin{array}{l}\text { - Escolha da empresa certa; } \\
\text { - Existência de NIT universitário para administrar e } \\
\text { legalizar o processo; } \\
\text { - Empresa com departamento de P\&D e pessoal } \\
\text { qualificado; } \\
\text { - Empresa ter interlocutor especializado em } \\
\text { propriedade intelectual; } \\
\text { - Alta qualidade, simplicidade e perspectiva de } \\
\text { retorno econômico da tecnologia; } \\
\text { - Inventor altamente capacitado tecnicamente, } \\
\text { acessível e envolvido com o processo; } \\
\text { - Estabelecimento de um cronograma breve de } \\
\text { atividades e de execução. }\end{array}$ \\
\hline
\end{tabular}


universidade pela exploração comercial da tecnologia, podem ser calculados a partir do faturamento bruto ou líquido obtido pela empresa. No primeiro caso, o percentual é aplicado sobre o valor total de vendas, já no segundo, são deduzidos os impostos e taxas. Conforme se verifica na seção seguinte, este aspecto foi objeto de longas discussões nos contratos referentes à USP e UFSCar, quais sejam os que não possuíam relacionamento prévio entre a universidade e a empresa para licenciamento de patentes. A definição de royalties em propriedade intelectual de inventos surgidos dentro de convênios de pesquisa (Unifesp e Unesp) não demonstrou dificuldade nem no caso da Unicamp, no qual a empresa já era coproprietária.

Cabe ainda ressaltar que as faixas de royalties praticadas nos contratos estão convergentes com as praticadas no mercado. Isto pode ser visto tomando os padrões médios de taxas de royalties utilizadas para cada segmento de aplicação das tecnologias. Com base em dados de Russell (2007), essas taxas médias são as seguintes para os respectivos casos estudados: USP, indústria de cosméticos com média em 4\%; Unesp, Unicamp e UFSCar, indústria química, com média em 3\%; e Unifesp, indústria farmacêutica, 4,5\%.

Ressalta-se que, no caso da Unicamp, uma vez que a empresa é coproprietária do pedido de patente, a taxa de royalties tende a ser menor. No entanto, embora esta situação tenha se repetido no caso na Unesp, o percentual de royalties negociado foi acima da média, isto é, $4 \%$. Isto pode ter relação com o porte da empresa licenciada e com a escala de produção prevista para exploração comercial, dentro da lógica de quanto maior escala menor percentual de royalties, já que no caso da Unicamp tratou-se de empresa multinacional e da Unesp de uma pequena empresa, conforme definições de porte de empresas proposto por SEBRAE (2001).

\subsection{Análise dos fatores de dificuldade e de apoio na transferência de tecnologia}

A partir das entrevistas, foram conseguidos dados qualitativos para uma análise do relacionamento entre universidade e empresa e os fatores de dificuldade e de apoio na prática da transferência de tecnologia. $\mathrm{O}$ quadro 1 apresenta os dados de forma conjunta permitindo uma comparação entre os processos verificados junto às universidades.

Como um fator de dificuldade identificado em todos os processos destacou-se a morosidade da área jurídicoadministrativa para efetivação do contrato. Ficou claro que os envolvidos julgaram que era possível consolidar a parceria mais rapidamente, apresentando como desestímulo o tempo de aguardo e, algumas vezes, a desinformação durante os trâmites. A fixação de um percentual de royalties para repasse à universidade foi apontada como um momento delicado das tratativas, isso em especial nas 2 ocorrências em que a universidade era a única proprietária da patente e realizou licenciamento com exclusividade.

Caso particular no tocante às dificuldades percebidas no processo da USP foi o uso de processo licitatório para oferta da tecnologia e escolha da empresa, pois ainda não havia sido regulamentada a Lei de Inovação, o que onerou em tempo e flexibilidade nas tratativas. No caso da Unicamp houve queixas quanto à dificuldade no uso e alocação de recursos oriundos da empresa, sendo esta inflexibilidade razão de um aproveitamento não ideal.

Os fatores de apoio mais relevantes foram: a existência de uma estrutura de apoio na universidade para patenteamento e comercialização de tecnologia, portanto, uma referência aos NIT; o retorno pecuniário para os inventores a título de estímulo; nível de confiança da empresa nos cientistas envolvidos; experiência boa de relacionamento prévio entre as partes envolvidas; e a existência de um setor específico na empresa para tratativas dessa natureza.

Alguns aspectos mais particulares foram observados, mas necessitam ser destacados. O principal deles foi a existência de um documento de patente bem redigido e vigente. A empresa parceira da USP enfatizou esse aspecto como determinante para a conveniência de obter licença da universidade. Também, o uso de instrumentos formais para a parceria foi tido como papel de segurança jurídica e administrativa dos processos, item bastante valorizado pelas empresas.

\subsection{Desafios para o aperfeiçoamento da transferência de tecnologia no Brasil}

Como resultado da análise das políticas de propriedade intelectual e dos fatores de dificuldade e de apoio à transferência de tecnologia envolvendo a propriedade intelectual, foi possível elencar os principais desafios por que passam essas universidades no tocante ao objeto central deste trabalho relativo à gestão tecnológica pró-patenteamento e transferência de tecnologias. Esses indicativos são restritos aos resultados obtidos junto às instituições caracterizadas na subseção 6.1, não podendo ser generalizados. A despeito disso, eles suscitam aspectos de possível interesse em demais universidades com perfis e objetivos semelhantes, sobretudo, no contexto brasileiro.

Em princípio, o aspecto da proteção do conhecimento está mais consolidado nas universidades, mesmo porque as ferramentas para sua gestão já estão mais difundidas. Podem ser destacados os seguintes desafios para todas as instituições estudadas:

Proteção internacional da tecnologia: na perspectiva de mercado global e ganhos por geração de economias de escala, é imprescindível a extensão da patente para territórios como EUA, Europa e Japão, porém não há recursos financeiros para tanto. As alternativas existentes são o pleito junto a agências de fomento e a realização de parcerias com empresas que arquem com os custos do patenteamento internacional. 
Gestão de recursos humanos: observa-se a necessidade de fixação de pessoal qualificado nos NIT, devido à escassez desse perfil de profissional e à alta rotatividade dos colaboradores em caráter de contrato temporário ou estágio.

Morosidade dos trâmites internos às universidades. Necessidade de sensibilizar outros setores da universidade visando maior eficiência administrativa: mostrou-se como recorrente queixa dos atores do processo de transferência de tecnologia. $\mathrm{O}$ desafio é promover uma reestruturação processual e jurídica para os casos de comercialização da propriedade intelectual, considerar alternativas para análise dos colegiados acadêmicos sobre esses processos (amostragem, organização específica competente, prioridade no fluxo desses processos a seguir cronograma pré-estabelecido).

Marketing de tecnologia universitária. A identificação de parceiros empresariais adequados para licenciamento de patentes ou realização de $\mathrm{P} \& \mathrm{D}$ conjunto mostra-se uma tarefa para o ETT pouco desbravada.

Valoração de tecnologia: realizar de forma mais profissional a mensuração econômica dos inputs (neste caso, capital financeiro e intelectual aplicados) de pesquisa, bem como de seus resultados. $\mathrm{O}$ avanço necessário se refere principalmente ao desenvolvimento de metodologias confiáveis e objetivas de suporte a negociações.

\section{Considerações finais}

A gestão da propriedade intelectual e a transferência de tecnologia formalizada das universidades públicas no Estado de São Paulo têm ganhado importância em todos os casos. As evidências para tanto foram vistas quanto à existência de NIT nas universidades, o estabelecimento de políticas com foco nesta área, bem como pelo desempenho em patenteamento alcançado pelas universidades com vistas a uma tendência de crescimento.

Mais especificamente, as universidades estão se estruturando para uma gestão da propriedade intelectual mais adequada aos desafios da transferência de tecnologia. Neste sentido, a comercialização de tecnologias utilizando contratos que incluem a propriedade intelectual mostrou-se presente na realidade dos NIT das universidades. Com menos ênfase no caso da Unesp, todas as universidades já possuem dados organizados acerca do tema e atendem à demanda acadêmica quanto à solicitação da proteção de tecnologias. De modo geral, notou-se pelas entrevistas que os NIT da USP e da Unicamp se mostraram mais estruturados em termos de pessoal, já os NIT da UFSCar e da Unifesp possuem uma estrutura mais enxuta, tendo em vista serem universidades com um número menor de docentes/pesquisadores.

Essas transformações têm ocorrido desde um momento anterior à Lei de Inovação regulamentada em 2005 , confirmando que o movimento do governo brasileiro em direção ao marco legal para a área de propriedade intelectual e de transferência de tecnologia, a despeito de possíveis aspectos específicos, tem, como um todo, aderência à realidade das universidades públicas instaladas no Estado de São Paulo.

O fato de o movimento de regulamentação e profissionalização da gestão de tecnologia em universidades ser ainda recente no Brasil cria dificuldades para traçar paralelos bem definidos com os casos internacionais abordados. No entanto, é possível ensejar algumas considerações. Corroborando indicativos de Graff, Heiman e Zilberman (2002), também se verificou nos casos estudados o importante papel do inventor no processo de transferência de tecnologia, tendo em vista contatos com as potenciais empresas parceiras no tocante ao marketing da tecnologia e quanto à colaboração para transferência de conhecimento tácito.

É relevante destacar ainda a magnitude dos depósitos de pedidos de patente das universidades, já que apenas as 5 instituições objeto deste estudo acumularam somente no período de 1999 a 2006 o número de 653 pedidos/patentes. Certamente isso indica primeiro um importante incremento da proteção intelectual acadêmica por patentes e, em segundo lugar, reforço ao papel dos NIT em gerir informações e ativos intelectuais das universidades, de acordo com seus objetivos.

Sob o ponto de vista do desempenho em proteção e transferência de tecnologia, desconsiderando as proporções de tamanho das comunidades acadêmicas, e considerando a experiência acumulada pela prática de transferência de tecnologia, a Unicamp mostrou-se a instituição mais avançada no que se refere ao número de pedidos/patentes. Quanto à transferência dessas tecnologias, ela também se destaca com o maior número de contratos assinados. A USP manifestou grande reação ao contexto atual seja visto pelo crescimento em patentes depositadas e também por uma estruturação promovida em seu NIT, porém com iniciativas de transferência de tecnologia mais recentes.

A UFSCar demonstrou um grande salto nos últimos 3 anos quanto à estruturação e efetivação de registros de propriedade intelectual, tendo realizado 3 licenciamentos até o momento de uma carteira de patentes de aproximadamente 30 tecnologias. Esse índice de $10 \%$ remete aos verificados em universidades estadunidenses mais experientes nessa prática como a Universidade da Califórnia e o Instituto de Tecnologia de Massachusetts (MIT). Entretanto, a escala do número de processos de proteção e de negociação entre essas instituições dos EUA e as instituições brasileiras são incomparáveis, seja no caso da UFSCar ou em todos os outros, reafirmando a incipiência dessa realidade no Brasil.

Os dados de concentração de áreas no licenciamento e aplicação de recursos de royalties relatados por Graff, Heiman e Zilberman (2002) evidenciam a distância entre a experiência internacional de vanguarda em transferência de 
tecnologia para com as universidades estudadas. Entretanto, há razões para acreditar que uma gestão cada vez mais aperfeiçoada da tecnologia gerada nas universidades poderá permitir a elas intensificar mais essa forma de contribuição para a sociedade, qual seja a utilização da ciência para o desenvolvimento econômico do País por meio da valorização de sua propriedade intelectual.

Como indicativo para futuros estudos, é útil considerar o elenco de desafios para o aperfeiçoamento da transferência de tecnologia em universidades brasileiras feito na subseção 6.6, com destaque para a ampliação do conhecimento sobre gestão de recursos humanos nesta área específica e ferramentas envolvendo valoração e marketing de tecnologia. Ainda, é possível levantar questões sobre os impactos econômicos e sociais da absorção de tecnologia universitária por empresas no caso brasileiro a fim de averiguar resultados deste processo de forma mais aprofundada na indústria e na sociedade de forma ampla.

\title{
Technology management in universities: an analysis of patenting and support and difficulty factors in technology transfer in São Paulo State
}

\begin{abstract}
Technology management in Brazilian public universities has gained increasing importance within the Brazilian innovation system. The Innovation Act of 2004 provides specific legal guidance on intellectual property, technical cooperation and technology transfer, favoring the intensification of these processes. The objective of this work was to understand the institutional policies and challenges for technology transfer in the public universities, as well as to identify forces and obstacles related to technology commercialization. The kind of analyses was qualitative, and for the empirical part of the work, the strategy of case studies was used in institutions such as: USP, Unesp, Unicamp, Unifesp e UFSCar. Using technology transfer contracts from each one of them, this article reveals key aspects, forces and obstacles within that practice. An increase in intellectual property and technology commercialization activities was noted in all cases, but this is still recent.
\end{abstract}

Keywords: Technology management. Public universities. Intellectual property.

\section{Referências biliográficas}

ALVES - MAZZOTTI, A. J.; GEWANDSZNAJDER, F. O método nas ciências naturais e sociais: pesquisa quantitativa e qualitativa. 2 ed. São Paulo: Pioneira, 1998.

ASSOCIATION OF UNIVERSITY TECHNOLOGY MANAGERS AUTM. US Licensing Survey, FY 2004: survey summary of technology licensing (and related) performance for U.S. academic and nonprofit institutions and technology investment firms. Deerfield, 2005. p. 1-71. (AUTM report)

BRASIL. Lei n. 9.279, de 14 de Maio de 1996. Regula direitos e obrigações relativos à propriedade industrial. Diário Oficial da União, Poder Executivo, Brasília, DF, 15 de Maio de 1996. Disponível em: <http://www.planalto.gov.br/ccivil_03/Leis/ L9279.htm>. Acesso em: 12 de Outubro de 2009.

BRASIL. Lei n. 10.973, de 02 de Dezembro de 2004. Dispõe sobre incentivos à inovação e à pesquisa científica e tecnológica no ambiente produtivo e dá outras providências. Diário Oficial da União, Poder Executivo, Brasília, DF, 03 de Dezembro de 2004. Disponível em: <https://www.planalto.gov.br/ccivil_03/_Ato20042006/2004/Lei/L10.973.htm>. Acesso em: 12 de Março de 2005 .
CHAGAS, E. N. Apreensão, implementação e gestão da propriedade intelectual nas instituições públicas de ensino superior. Viçosa, 2004. 134 p. Dissertação (Mestrado) Universidade Federal de Viçosa - UFV.

CHAPPLE, W. et al. Assessing the relative performance of U.K university technology transfer offices: parametric and non-parametric evidence. Research Policy, v. 34, n. 3, p. 369-384, 2005.

CONSELHO NACIONAL DE DESENVOLVIMENTO CIENTÍFICO E TECNOLÓGICO - CNPQ. Súmula estatística: Diretório de Grupos de Pesquisa no Brasil. Brasília: Ministério de Ciência e Tecnologia, 2009. Disponível em: <http://dgp.cnpq.br/censos/ sumula_estat/index_grupo.htm>. Acesso em: 05 de Outubro de 2009.

DI BLASI Jr., C. G.; GARCIA, M. A. S.; MENDES, P. P. M. A. A propriedade industrial: os sistemas de marcas, patentes e desenhos industriais analisados a partir da Lei n. 9279, de 14 de Maio de 1996. Rio de Janeiro: Forense, 2000.

ETZKOWITZ, H. The evolution of the entrepreneurial university. International Journal Technology and Globalization, v. 1, n. 1, p. 64-77, 2004. 
ETZKOWITZ, H.; STEVENS, A. J. Toward industrial policy: the university's role in government initiatives to assist small, innovative companies in the United States. In: ETZKOWITZ, H.; WEBSTER, A.; HEALEY, P. (Orgs.). Capitalizing knowledge: new intersections of industry and academia. Albany: The State University of New York, 1998.

FRIEDMAN, J.; SILBERMAN, J. University technology transfer: do incentives, management and location matter? Journal of Technology Transfer, n. 28, p. 17-30, 2003.

FUJINO, A.; STAL, E. Gestão da propriedade intelectual na universidade pública brasileira: diretrizes para licenciamento e comercialização. In: SIMPÓSIO DE GESTÃO DA INOVAÇÃO TECNOLÓGICA, 23, 2004, Curitiba. Anais... São Paulo: Universidade de São Paulo, 2004. p. 912-927.

GARNICA, L. A.; OLIVEIRA, R. M.; TORKOMIAN, A. L. V. Propriedade intelectual e titularidade de patentes universitárias: um estudo piloto na Universidade Federal de São Carlos - UFSCar. In: SIMPÓSIO DE GESTÃO DA INOVAÇÃO TECNOLÓGICA, 24, 2004, Gramado. Anais... Gramado: Associação Nacional de Pós-Graduação e Pesquisa em Administração, 2006.

GEUNA, A.; NESTA. L. University patenting and its effects on academic research: the emerging European evidence. Research Policy, v. 35, p. 790-807, 2006.

GRAFF, G.; HEIMAN, A.; ZILBERMAN, D. University research and offices of technology transfer. California Management Review, v. 45, n. 1, p. 88-115, 2002.

GUSMÃO, R. Práticas e políticas internacionais de colaboração ciência-indústria. Revista Brasileira de Inovação, v. 1, n. 2, p. 327-360, 2002.

HAASE, H.; ARAÚJO, E. C.; DIAS, J. Inovações vistas pelas patentes: exigências frente às novas funções das universidades. Revista Brasileira de Inovação, v. 4, n. 2, p. 329-362, 2005.

LOCKETT, A. et al. The creation of spin-off firms at public research institutions: managerial and policy implications. Research Policy, v. 34, p. 981-993, 2005.

Managing Intellectual Property. Bayh-Dole's influence worldwide. London, 2006.

MARKMAN, G. et al. Innovation speed: transferring university technology to market. Research Policy, v. 34, n. 7, p. 10581075, 2005.

MCADAM, R. et al. Defining and improving technology transfer business and management process in university innovation centres. Technovation, n. 20, p. 1-12, 2004.

MINISTÉRIO DE CIÊNCIA E TECNOLOGIA - MCT. Indicadores Nacionais de Ciência e Tecnologia. Brasília, 2002. Disponível em: <www.mct.gov.br>. Acesso em: 06 de Novembro de 2005 .
MINISTÉRIO DE CIÊNCIA E TECNOLOGIA - MCT. Indicadores. Brasília, 2009. Disponível em: <http://www.mct.gov.br/index. php/content/view/29140.html>. Acesso em: 12 de Outubro de 2009.

MOWERY, D. C. et al. The growth of patenting and licensing by U.S. universities: an assessment of the effects of the Bayh-Dole act of 1980. Research Policy, v. 30, n. 1, p. 99-119, 2001.

MOWERY, D. C.; SHANE, S. Introduction to the special issue on university entrepreneurship and technology transfer. Management Science, v. 48, n. 1, p. V-IX, 2002.

ROGERS, E. M.; YIN, J.; HOFFMANN, J. Assessing the effectiveness of technology transfer offices at U.S. research universities. The Journal of the Association of University Technology Managers, v. 12, p. 47-80, 2000. Disponível em <http://www. autm.net/pubs/journal/00/assessing.html>. Acesso em: $01 \mathrm{de}$ Março de 2004.

RUSSELL, L. P. Royalty rates for licensing intellectual property. New Jersey: John Wiley \& Sons, 2007.

RUIZ, A. U. Patentes y funcíon publica universitária na Europa: mitos e realidades. Revista Brasileira de Inovação, v. 4, n. 2, p. 391-423, 2005.

SCHOLZE, S.; CHAMAS, C. Instituições públicas de pesquisa e o setor empresarial: o papel da inovação e da propriedade intelectual. Parcerias Estratégicas, n. 8, p. 85-92. 2000.

SERVIÇO BRASILEIRO DE APOIO ÀS MICRO E PEQUENAS EMPRESAS - SEBRAE. MPES de base tecnológica: conceituação, formas de financiamento e análise de casos brasileiros. São Paulo, 2001. (relatório de pesquisa)

SEGATTO-MENDES, A. P.; SBRAGIA, R. O processo de cooperação universidade: empresa em universidades brasileiras. Revista de Administração, v. 37, n. 4, p. 58-71, 2002.

STAL, E.; FUJINO, A. A propriedade intelectual na universidade e o papel das agências de fomento. In: SIMPOSIO DE GESTÃO DA INOVAÇÃO TECNOLÓGICA, 22, 2002, Salvador. Anais... São Paulo: Universidade de São Paulo, 2002.

TERRA, B. A transferência de tecnologia em universidades empreendedoras: um caminho para a inovação tecnológica. Rio de Janeiro: Qualitymark, 2001.

WORLD INTELLECTUAL PROPERTY ORGANIZATIOn - WIPO. What is intellectual property? Switzerland, 2005. Disponível em: <http://www.wipo.int/about-ip/en/patents.html>. Acesso em: 07 de Março de 2005.

YIN, R. K. Estudo de caso: planejamento e métodos. 2 ed. Porto Alegre: Bookman, 2001.

YISSUM TECHNOLOGY TRANSFER COMPANY OF THE HEBREW UNIVERSITY OF JERUSALEM. Technology transfer process. Israel, 2006. Disponível em: <www.yissum. co.il/web/defaut.asp>. Acesso em: 17 de Março de 2006. 


\section{Sobre os autores}

\section{Leonardo Augusto Garnica}

Agente de Inovação - Universidade de São Paulo - USP

Av.Trabalhador São-carlense, 400 , Edifício Q5, Centro, São Carlos, São Paulo, CEP 13566-590

e-mail: garnica@usp.br

\section{Ana Lúcia Vitale Torkomian}

Professora Doutora do Departamento de Engenharia de Produção - Universidade Federal de São Carlos Rod. Washington Luís 235, SP-310, São Carlos, São Paulo, CEP 13565-905

e-mail: torkomia@power.ufscar.br

Agradecimentos: Os autores agradecem aos revisores do presente artigo, à Fundação de Amparo a Pesquisa no Estado de São Paulo FAPESP o apoio ao projeto que resultou neste trabalho, e a todos os entrevistados e a suas respectivas instituições a colaboração no fornecimento de informações.

Recebido em 3/1/2008

Aceito em 30/11/2009 